\title{
Genetic Diversity and Aggressiveness of Fusarium spp. Isolated from Canola in Alberta, Canada
}

Yongyan Chen, Department of Agricultural, Food and Nutritional Science, University of Alberta, Edmonton, AB, T6G 2P5, Canada; Qixing Zhou, Crop Diversification Centre North, Alberta Agriculture and Rural Development, Edmonton, AB, T5Y 6H3, Canada; Stephen E. Strelkov, Department of Agricultural, Food and Nutritional Science, University of Alberta, Edmonton; and Sheau-Fang Hwang, Crop Diversification Centre North, Alberta Agriculture and Rural Development, Edmonton

\begin{abstract}
Chen, Y., Zhou, Q., Strelkov, S. E., and Hwang, S.-F. 2014. Genetic diversity and aggressiveness of Fusarium spp. isolated from canola in Alberta, Canada. Plant Dis. 98:727-738.

Canola (Brassica napus) is one of the most economically important oilseed crops in Canada. Fusarium seedling blight is a root disease with the potential to cause severe yield reductions in canola. Fusarium spp. are commonly isolated root pathogens from fields in Alberta. Fusarium infection can also cause root rot in adult plants. In this study, 128 isolates identified as Fusarium spp. were recovered from field soils in central Alberta and from the roots of diseased canola plants with typical Fusarium seedling blight symptoms. Six species of Fusarium were identified, with Fusarium acuminatum as the predomi-

nant species (57 of 128 isolates, 44.5\%). Phylogenetic analyses based on the translation elongation factor $1-\alpha$ and the internal transcribed spacer sequence data were used for evaluation of genetic variations, and also used for Fusarium spp. identification in combination with morphological characteristics and polymerase chain reaction-based analyses. Based on disease ratings in pathogenicity tests, six isolates of F. avenaceum showed high aggressiveness on canola. Also, the aggressiveness varied within all Fusarium spp. No correlation was observed between aggressiveness and the geographic origin of the isolates.
\end{abstract}

Canola (Brassica napus L.) is one of the most economically important oilseed crops in Canada, and its production has significantly increased in recent years (22). In Canada, most canola is grown mostly on the prairies, consisting of the provinces of Alberta, Saskatchewan, and Manitoba, where a cool climate and fertile soils provide ideal conditions for growing the crop. Diseases caused by Fusarium spp. on canola include Fusarium seedling blight, Fusarium root rot, and Fusarium wilt. Fusarium seedling blight, caused by several species, is one of several seedling diseases in canola (3). Fusarium seedling blight may cause failure of seed to germinate, death of newly emerged seedlings (pre- and post-emergence damping-off), root rot in adult plants, and yield reductions (3). Fusarium wilt of canola, caused by Fusarium oxysporum and $F$. avenaceum, can also result in yield loss in susceptible cultivars $(4,25)$. Based on assays of soil samples from Saskatchewan, Fusarium spp. were the most common root pathogen in canola fields, followed by Pythium and Rhizoctonia spp.(22).

Because more than one species of Fusarium was isolated from canola $(3,22)$, the identification of the species and the evaluation of their virulence are important. However, the identification and evolutionary history of Fusarium spp. is quite complex. Species identification of Fusarium is based on morphological characteristics described in the taxonomic systems of Wollenweber and Reinking (44). However, the concept of a species within the genus has varied greatly between broader and narrower concepts (26). In addition, isolates within a particular species may vary considerably, both morphologically $(26,36)$ and genetically $(2,10,12,19)$, which has caused difficulties in species identification (26). However, molecular approaches have become more and more valuable for species identification and evaluation of the genetic variation among

Corresponding author: S.-F. Hwang, E-mail: sheau-fang.hwang@gov.ab.ca Accepted for publication 12 December 2013.

http://dx.doi.org/10.1094/PDIS-01-13-0061-RE

This article is in the public domain and not copyrightable. It may be freely reprinted with customary crediting of the source. The American Phytopathological Society, 2014.
Fusarium isolates. Some Fusarium spp. can be identified by using polymerase chain reaction (PCR) analysis with specific primer sets $(8,9,41)$. Studies of the population structure of Fusarium spp. by using this molecular approach are also helpful for clarifying the disease etiology and devising effective management strategies.

The translation elongation factor $1-\alpha(E F-1 \alpha)$ gene sequence has proven to be an excellent phylogenetic marker for resolving interand intraspecies relationships within the Fusarium species complex. This has led to the creation of a single locus database for species identification, FUSARIUM-ID v. 1.0 (15), which has been updated to a multiple sequence database FUSARIUM-ID (http://isolate.fusariumdb.org) at Pennsylvania State University's Department of Plant Pathology, and to the Fusarium MLST (http://www.cbs.knaw.nl/fusarium) at the CBS-KNAW Fungal Biodiversity Center (31). At the species level, the internal transcribed spacer (ITS) region of ribosomal (r)DNA is commonly used to identify and detect fungi based on the microbiological molecular phylogeny $(6,16,40)$. The ITS rDNA region has been formally proposed to the Consortium for the Barcode of Life for adoption as the primary fungal barcode marker (37), and has been added as one of the core plant barcodes for land plants $(5,7,27)$. Phylogenetic approaches are commonly used to identify taxonomic units in fungi and are often more effective than morphological methods (37).

In the present study, 128 isolates of Fusarium spp. were isolated from canola fields in Alberta. Species identification, genetic diversity, and phylogenetic relationships of these isolates were examined. Pathogenicity tests were also conducted to assess the aggressiveness of the Fusarium isolates.

\section{Materials and Methods}

Fungal isolation and purification. Soil samples and diseased canola seedlings were collected from a total of 120 canola fields in 10 counties in central Alberta during the summers of 2009, 2010, and 2011 (Table 1). For each soil sample, an aliquot of about 500 $\mathrm{ml}$ was placed in a 700-ml plastic cup which was sown with 10 seeds of 'Westar' canola, a cultivar that is susceptible to Fusarium root rot. The plants were grown in a greenhouse at about $25^{\circ} \mathrm{C}$, with a 12-h photoperiod. Root tips and stem crowns of the canola seedlings were harvested 2 to 3 weeks after seeding and gently washed under running tap water. The greenhouse-grown canola 
Table 1. Source of Fusarium isolates, their species identification, and median disease rating (MDR), mean rank (Ri), and estimated relative effects (pi) of root rot severity of Fusarium isolates on canola

\begin{tabular}{|c|c|c|c|c|c|c|c|c|}
\hline \multirow[b]{2}{*}{ Species, isolate } & \multirow[b]{2}{*}{ Location } & \multicolumn{2}{|c|}{ Species identification $^{\mathrm{a}}$} & \multirow[b]{2}{*}{ MDR } & \multirow[b]{2}{*}{$\mathbf{R i}$} & \multirow[b]{2}{*}{$\mathrm{p} i$} & \multicolumn{2}{|c|}{$\begin{array}{l}\text { Confidence interval }(95 \%) \text { for } \\
\text { relative treatment effect }\end{array}$} \\
\hline & & FaF/FaR & J1AF/J1AR & & & & Lower & Upper \\
\hline \multicolumn{9}{|c|}{ Fusarium avenaceum } \\
\hline F185 & Yellowhead & + & + & 3.7 & 75.8 & $0.84(0.009)$ & 0.68 & 0.91 \\
\hline F168 & Wetaskiwin & + & + & 3.7 & 74.8 & $0.83(0.009)$ & 0.72 & 0.89 \\
\hline F058a & Camrose & + & + & 3.6 & 73.8 & $0.81(0.009)$ & 0.72 & 0.88 \\
\hline F087 & Ponoka & + & + & 3.7 & 73.8 & $0.81(0.009)$ & 0.69 & 0.89 \\
\hline F169 & Wetaskiwin & - & + & 3.5 & 69.8 & $0.77(0.009)$ & 0.69 & 0.83 \\
\hline F085 & Parkland & - & + & 3.3 & 66.6 & $0.73(0.008)$ & 0.63 & 0.82 \\
\hline F066 & Leduc & - & + & 2.0 & 48.6 & $0.53(0.006)$ & 0.50 & 0.57 \\
\hline F119 & Strathcona & + & + & 2.0 & 42.6 & $0.47(0.005)$ & 0.39 & 0.55 \\
\hline F195 & Yellowhead & + & + & 1.3 & 36.9 & $0.40(0.004)$ & 0.32 & 0.50 \\
\hline F124 & Strathcona & + & + & 1.1 & 31.2 & $0.34(0.004)$ & 0.28 & 0.41 \\
\hline F108 & Strathcona & + & + & 0.8 & 26.2 & $0.29(0.003)$ & 0.20 & 0.40 \\
\hline F023 & Camrose & + & + & 0.9 & 25.6 & $0.28(0.003)$ & 0.21 & 0.37 \\
\hline F123 & Strathcona & + & + & 0.6 & 13.3 & $0.14(0.002)$ & 0.09 & 0.23 \\
\hline F058b & Camrose & + & + & 0.4 & 12.3 & $0.13(0.001)$ & 0.07 & 0.25 \\
\hline F122 & Strathcona & + & + & 0.4 & 11.4 & $0.12(0.001)$ & 0.06 & 0.28 \\
\hline \multicolumn{9}{|l|}{ F. acuminatum } \\
\hline F094 & Strathcona & + & _- & 2.6 & 301.8 & $0.96(0.006)$ & 0.91 & 0.98 \\
\hline F174 & Yellowhead & + & - & 3.1 & 327.7 & $0.95(0.006)$ & 0.77 & 0.98 \\
\hline F081 & Parkland & + & - & 2.4 & 281.3 & $0.93(0.005)$ & 0.88 & 0.96 \\
\hline F070 & Leduc & + & - & 2.4 & 313.1 & $0.89(0.005)$ & 0.73 & 0.96 \\
\hline F140 & Thorhild & + & - & 2.1 & 263.1 & $0.87(0.005)$ & 0.74 & 0.94 \\
\hline F116 & Strathcona & + & - & 2.3 & 294.8 & $0.82(0.005)$ & 0.54 & 0.95 \\
\hline F193 & Yellowhead & + & - & 2.1 & 257.5 & $0.81(0.005)$ & 0.65 & 0.91 \\
\hline F089 & Ponoka & + & - & 2 & 263.4 & $0.79(0.005)$ & 0.72 & 0.85 \\
\hline F101 & Strathcona & + & - & 1.6 & 224 & $0.79(0.005)$ & 0.58 & 0.91 \\
\hline F030 & Camrose & + & - & 1.8 & 220.1 & $0.77(0.004)$ & 0.42 & 0.93 \\
\hline F090 & Ponoka & + & - & 1.9 & 242.8 & $0.75(0.004)$ & 0.6 & 0.86 \\
\hline F172 & Wetaskiwin & + & - & 1.5 & 215.9 & $0.74(0.004)$ & 0.51 & 0.88 \\
\hline F115 & Strathcona & + & - & 2 & 270.6 & $0.72(0.004)$ & 0.56 & 0.84 \\
\hline F134 & Thorhild & + & - & 1.8 & 219.2 & $0.69(0.004)$ & 0.61 & 0.77 \\
\hline F083 & Parkland & - & - & 2 & 238.9 & $0.68(0.004)$ & 0.3 & 0.91 \\
\hline F061 & Leduc & + & - & 1.7 & 214.7 & $0.67(0.004)$ & 0.56 & 0.76 \\
\hline F086 & Parkland & + & _- & 2 & 252.1 & $0.67(0.004)$ & 0.37 & 0.87 \\
\hline F121 & Strathcona & + & - & 1.7 & 229.3 & $0.67(0.004)$ & 0.49 & 0.8 \\
\hline F163 & Wetaskiwin & - & - & 1.5 & 184.9 & $0.66(0.004)$ & 0.57 & 0.73 \\
\hline F194 & Yellowhead & + & - & 1.8 & 214.8 & $0.62(0.004)$ & 0.38 & 0.8 \\
\hline F192 & Yellowhead & + & - & 1.8 & 231.6 & $0.59(0.003)$ & 0.4 & 0.75 \\
\hline F011 & Barrhead & + & - & 1.3 & 159.2 & $0.57(0.003)$ & 0.29 & 0.8 \\
\hline F068 & Leduc & + & - & 1.7 & 217.2 & $0.57(0.003)$ & 0.23 & 0.85 \\
\hline F095 & Strathcona & + & - & 1.4 & 186.8 & $0.57(0.003)$ & 0.23 & 0.85 \\
\hline F002 & Barrhead & + & - & 1.6 & 207.7 & $0.56(0.003)$ & 0.44 & 0.68 \\
\hline $\mathrm{F} 150$ & Sturgeon & + & - & 1.6 & 221.3 & $0.56(0.003)$ & 0.42 & 0.69 \\
\hline F082 & Parkland & + & - & 1.7 & 222.6 & $0.54(0.003)$ & 0.45 & 0.63 \\
\hline F141 & Sturgeon & + & - & 1.2 & 133.9 & $0.50(0.003)$ & 0.26 & 0.73 \\
\hline F196 & Yellowhead & + & - & 1.5 & 190.7 & $0.50(0.003)$ & 0.33 & 0.67 \\
\hline F161 & Wetaskiwin & - & - & 1.2 & 141.8 & $0.49(0.003)$ & 0.3 & 0.67 \\
\hline F147 & Sturgeon & - & - & 1.4 & 148.9 & $0.48(0.003)$ & 0.42 & 0.54 \\
\hline F151 & Sturgeon & + & - & 1.5 & 177.8 & $0.47(0.003)$ & 0.23 & 0.73 \\
\hline F133 & Thorhild & - & - & 1 & 115.1 & $0.46(0.003)$ & 0.24 & 0.69 \\
\hline F099 & Strathcona & + & - & 0.8 & 133.8 & $0.44(0.003)$ & 0.11 & 0.84 \\
\hline F142 & Sturgeon & - & - & 1.8 & 201.6 & $0.44(0.003)$ & 0.09 & 0.87 \\
\hline F084 & Parkland & + & _- & 1.5 & 180.2 & $0.41(0.002)$ & 0.17 & 0.7 \\
\hline F143 & Sturgeon & + & - & 1.3 & 160.6 & $0.41(0.002)$ & 0.27 & 0.57 \\
\hline F114 & Strathcona & + & - & 0.9 & 104.8 & $0.40(0.002)$ & 0.19 & 0.65 \\
\hline F049 & Camrose & + & - & 0.6 & 79.2 & $0.36(0.002)$ & 0.13 & 0.68 \\
\hline F109 & Strathcona & - & - & 1.3 & 155.2 & $0.36(0.002)$ & 0.19 & 0.58 \\
\hline F102 & Strathcona & + & - & 1.1 & 113.6 & $0.34(0.002)$ & 0.24 & 0.46 \\
\hline F037 & Camrose & + & - & 0.9 & 84.8 & $0.32(0.002)$ & 0.24 & 0.41 \\
\hline F078 & Parkland & - & - & 1.2 & 136.8 & $0.31(0.002)$ & 0.16 & 0.52 \\
\hline F034 & Camrose & + & - & 0.9 & 90.3 & $0.26(0.002)$ & 0.15 & 0.42 \\
\hline F092 & Strathcona & + & - & 1 & 99.1 & $0.26(0.002)$ & 0.14 & 0.45 \\
\hline F026 & Camrose & + & - & 1 & 97 & $0.24(0.001)$ & 0.16 & 0.35 \\
\hline F053 & Camrose & + & - & 1.2 & 123.5 & $0.23(0.001)$ & 0.1 & 0.45 \\
\hline F031 & Camrose & + & - & 0.8 & 64.6 & $0.22(0.001)$ & 0.13 & 0.35 \\
\hline F048 & Camrose & + & - & 0.7 & 83.2 & $0.21(0.001)$ & 0.07 & 0.51 \\
\hline F050 & Camrose & + & - & 0.5 & 45.1 & $0.20(0.001)$ & 0.08 & 0.43 \\
\hline F051 & Camrose & + & - & 0.9 & 91.8 & $0.19(0.001)$ & 0.07 & 0.46 \\
\hline F036 & Camrose & + & - & 1 & 97.4 & $0.14(0.001)$ & 0.09 & 0.22 \\
\hline & & & & & & & (con & n next page) \\
\hline
\end{tabular}

${ }^{\text {a }}$ Results of polymerase chain reaction-based assays with both primer sets; $+=$ target band observed and $-=$ target band absent. 
tissues and the diseased samples from the canola fields were surface sterilized with $1 \%$ bleach for $30 \mathrm{~s}$ and washed under running tap water. All the tissues were placed on fresh Difco potato-dextrose agar (PDA) plates (Becton, Dickinson and Company) for 2 days at room temperature with 12-h lighting, then transferred to peptone-pentachloronitrobenzene medium (29) and incubated for 10 to 14 days with $12 \mathrm{~h}$ lighting at room temperature. Single-conidium isolates were established and cultured on PDA for 13 to 15 days at room temperature and stored at $4{ }^{\circ} \mathrm{C}$ for later use (26).

Table 1. (continued from preceding page)

\begin{tabular}{|c|c|c|c|c|c|c|c|c|}
\hline \multirow[b]{2}{*}{ Species, isolate } & \multirow[b]{2}{*}{ Location } & \multicolumn{2}{|c|}{ Species identification $^{\mathbf{a}}$} & \multirow[b]{2}{*}{ MDR } & \multirow[b]{2}{*}{$\mathbf{R i}$} & \multirow[b]{2}{*}{ pi } & \multicolumn{2}{|c|}{$\begin{array}{l}\text { Confidence interval }(95 \%) \text { for } \\
\text { relative treatment effect }\end{array}$} \\
\hline & & FaF/FaR & J1AF/J1AR & & & & Lower & Upper \\
\hline F056 & Camrose & + & - & 0.4 & 29.4 & $0.14(0.001)$ & 0.08 & 0.23 \\
\hline F097 & Strathcona & + & - & 0.5 & 64.3 & $0.11(0.001)$ & 0.03 & 0.34 \\
\hline F047 & Camrose & + & - & 0.6 & 48.3 & $0.07(0.000)$ & 0.04 & 0.13 \\
\hline F052 & Camrose & + & - & 0.4 & 45.8 & $0.07(0.000)$ & 0.03 & 0.19 \\
\hline F027 & Camrose & + & - & 0.5 & 24.5 & $0.05(0.000)$ & 0.02 & 0.15 \\
\hline \multicolumn{9}{|l|}{ F. culmorum } \\
\hline F001 & Barrhead & - & - & 1.5 & 25.8 & $0.70(0.020)$ & 0.50 & 0.83 \\
\hline F167 & Wetaskiwin & - & - & 1.3 & 25.2 & $0.69(0.019)$ & 0.49 & 0.81 \\
\hline F175 & Yellowhead & - & - & 1.2 & 24.8 & $0.67(0.019)$ & 0.49 & 0.80 \\
\hline F135 & Thorhild & - & - & 0.7 & 16.1 & $0.43(0.012)$ & 0.30 & 0.58 \\
\hline F014 & Barrhead & - & - & 0.4 & 10.8 & $0.28(0.008)$ & 0.17 & 0.47 \\
\hline F054 & Camrose & - & - & 0.2 & 8.4 & $0.22(0.006)$ & 0.12 & 0.47 \\
\hline \multicolumn{9}{|l|}{ F. equiseti } \\
\hline F004 & Barrhead & - & - & 1.9 & 118.6 & $0.94(0.007)$ & 0.86 & 0.96 \\
\hline F139 & Thorhild & - & - & 1.4 & 99.1 & $0.78(0.006)$ & 0.63 & 0.88 \\
\hline F179 & Yellowhead & - & - & 1.1 & 90.8 & $0.72(0.006)$ & 0.60 & 0.81 \\
\hline F155 & Wetaskiwin & - & - & 1.2 & 87.1 & $0.69(0.005)$ & 0.45 & 0.85 \\
\hline F006 & Barrhead & - & - & 0.9 & 81.9 & $0.65(0.005)$ & 0.44 & 0.80 \\
\hline F069 & Leduc & - & - & 1.3 & 79.9 & $0.63(0.005)$ & 0.34 & 0.84 \\
\hline F103 & Strathcona & - & - & 0.9 & 77.3 & $0.61(0.005)$ & 0.52 & 0.69 \\
\hline F003 & Barrhead & - & - & 0.9 & 71.3 & $0.56(0.004)$ & 0.34 & 0.76 \\
\hline F106 & Strathcona & - & - & 0.9 & 71.2 & $0.56(0.004)$ & 0.34 & 0.76 \\
\hline F100 & Strathcona & - & - & 0.8 & 68.6 & $0.54(0.004)$ & 0.39 & 0.68 \\
\hline F020 & Barrhead & - & - & 0.7 & 67.4 & $0.53(0.004)$ & 0.36 & 0.70 \\
\hline F044 & Camrose & - & - & 0.6 & 63.8 & $0.50(0.004)$ & 0.31 & 0.69 \\
\hline F045 & Camrose & - & - & 0.7 & 58.3 & $0.46(0.004)$ & 0.29 & 0.64 \\
\hline F007 & Barrhead & - & - & 0.5 & 49.5 & $0.39(0.003)$ & 0.22 & 0.60 \\
\hline F041 & Camrose & - & - & 0.6 & 45.6 & $0.36(0.003)$ & 0.22 & 0.53 \\
\hline F018 & Barrhead & - & - & 0.6 & 44.9 & $0.35(0.003)$ & 0.21 & 0.53 \\
\hline F075 & Parkland & - & - & 0.5 & 42.5 & $0.33(0.003)$ & 0.16 & 0.57 \\
\hline F118 & Strathcona & - & - & 0.4 & 39.9 & $0.31(0.002)$ & 0.16 & 0.54 \\
\hline F015 & Barrhead & - & - & 0.3 & 31.3 & $0.24(0.002)$ & 0.13 & 0.42 \\
\hline F012 & Barrhead & - & - & 0.0 & 24.2 & $0.19(0.001)$ & 0.06 & 0.54 \\
\hline F019 & Barrhead & - & - & 0.2 & 20.3 & $0.16(0.001)$ & 0.11 & 0.23 \\
\hline \multicolumn{9}{|l|}{ F. torulosum } \\
\hline F186 & Yellowhead & - & - & 1.7 & 156.9 & $0.97(0.012)$ & 0.94 & 0.98 \\
\hline F137 & Thorhild & - & - & 1.0 & 106.7 & $0.86(0.010)$ & 0.75 & 0.92 \\
\hline F064 & Leduc & - & - & 1.1 & 112.3 & $0.85(0.010)$ & 0.65 & 0.94 \\
\hline F184 & Yellowhead & - & - & 1.2 & 123.9 & $0.85(0.010)$ & 0.65 & 0.94 \\
\hline F191 & Yellowhead & - & - & 1.2 & 115.6 & $0.84(0.010)$ & 0.76 & 0.90 \\
\hline F190 & Yellowhead & - & - & 1.5 & 144.8 & $0.82(0.010)$ & 0.69 & 0.90 \\
\hline F180 & Yellowhead & - & - & 1.3 & 117.8 & $0.77(0.009)$ & 0.62 & 0.86 \\
\hline F131 & Thorhild & - & - & 0.3 & 53.8 & $0.75(0.009)$ & 0.57 & 0.87 \\
\hline F166 & Wetaskiwin & - & - & 1.3 & 120.2 & $0.71(0.008)$ & 0.63 & 0.78 \\
\hline F110 & Strathcona & - & - & 1.1 & 114.3 & $0.69(0.008)$ & 0.59 & 0.78 \\
\hline F197 & Yellowhead & - & - & 1.2 & 120.9 & $0.69(0.008)$ & 0.60 & 0.77 \\
\hline F162 & Wetaskiwin & - & - & 0.9 & 94.6 & $0.56(0.007)$ & 0.47 & 0.64 \\
\hline F164 & Wetaskiwin & - & - & 1.0 & 104.1 & $0.56(0.007)$ & 0.47 & 0.64 \\
\hline F024 & Camrose & - & - & 0.4 & 44.0 & $0.53(0.006)$ & 0.47 & 0.58 \\
\hline F145 & Sturgeon & - & - & 0.8 & 71.6 & $0.47(0.006)$ & 0.38 & 0.56 \\
\hline F149 & Sturgeon & - & - & 0.6 & 44.2 & $0.44(0.005)$ & 0.38 & 0.50 \\
\hline F153 & Sturgeon & - & - & 0.8 & 69.4 & $0.41(0.005)$ & 0.35 & 0.47 \\
\hline F021 & Camrose & - & - & 0.6 & 56.5 & $0.39(0.005)$ & 0.32 & 0.47 \\
\hline F176 & Yellowhead & - & - & 0.7 & 71.7 & $0.37(0.004)$ & 0.28 & 0.48 \\
\hline F105 & Strathcona & - & - & 0.7 & 67.4 & $0.30(0.004)$ & 0.24 & 0.37 \\
\hline F157 & Wetaskiwin & - & - & 0.6 & 52.0 & $0.23(0.003)$ & 0.17 & 0.31 \\
\hline F148 & Sturgeon & - & - & 0.5 & 48.3 & $0.19(0.002)$ & 0.13 & 0.27 \\
\hline F187 & Yellowhead & - & - & 0.6 & 46.1 & $0.19(0.002)$ & 0.13 & 0.27 \\
\hline F076 & Parkland & - & - & 0.6 & 49.8 & $0.16(0.002)$ & 0.09 & 0.30 \\
\hline F146 & Sturgeon & - & - & 0.6 & 52.0 & $0.16(0.002)$ & 0.09 & 0.30 \\
\hline F171 & Wetaskiwin & - & - & 0.6 & 57.0 & $0.13(0.002)$ & 0.08 & 0.19 \\
\hline F065 & Leduc & - & - & 1.2 & 95.5 & $0.08(0.001)$ & 0.04 & 0.18 \\
\hline F107 & Strathcona & - & - & 0.4 & 33.8 & $0.02(0.000)$ & 0.02 & 0.06 \\
\hline \multicolumn{9}{|l|}{ F. redolens } \\
\hline F125 & Strathcona & - & - & - & - & - & - & - \\
\hline
\end{tabular}


DNA extraction, PCR amplification, sequencing, and identification of species. Prior to DNA extraction, all isolates were subcultured on PDA for 10 to 14 days at room temperature. Approximately $25 \mathrm{mg}$ of mycelium was collected from a PDA plate of each isolate with a sterilized toothpick for fungal genomic DNA extraction using the modified rapid mini-preparation method of Feng et al. (13). The DNA concentration and quality was estimated using a Thermo Scientific NanoDrop 1000 Spectrophotometer (Fisher Scientific) with the default set for DNA assays. In total, 128 isolates were tested by PCR using two $F$. avenaceum-specific primer pairs, J1AF/J1AR (41) and FaF/FaR (9) (Table 2). The PCR reactions were amplified in a final volume of $15 \mu$, which contained $1 \times$ PCR buffer (1.5 mM $\mathrm{MgCl}_{2}$ and $125 \mu \mathrm{M}$ each dNTP), $250 \mathrm{nM}$ each primer, 0.5 unit of GoTaq polymerase (Promega Corp.), and 25 to $60 \mathrm{ng}$ of genomic DNA. Thermocycler conditions consisted of an initial heat denaturation step at $95^{\circ} \mathrm{C}$ for $3 \mathrm{~min}$; 38 cycles of $30 \mathrm{~s}$ at $95^{\circ} \mathrm{C}, 30 \mathrm{~s}$ at $58^{\circ} \mathrm{C}\left(60^{\circ} \mathrm{C}\right.$ for $\left.\mathrm{FaF} / \mathrm{FaR}\right)$, and $40 \mathrm{~s}$ at $72^{\circ} \mathrm{C}$; followed by a final elongation step of $5 \mathrm{~min}$ at $72^{\circ} \mathrm{C}$. The amplicons obtained were mixed with a safegreen loading dye (Applied Biological Materials) and separated on a $1.2 \%$ agarose gel in $1 \times$ Tris-acetate-EDTA buffer at $100 \mathrm{~V}$ for $1.2 \mathrm{~h}$. The gels were visualized under UV light with a Gel DocTM XR System (Bio-Rad).

The translation EF- $1 \alpha$ and the ITS region of 128 isolates were amplified with the primer sets EF-1/EF-2 (32) and ITS4/ITS5 (43) (Table 2), respectively, in a final reaction volume of $30 \mu \mathrm{l}$. Each amplification reaction mixture contained $1 \times$ PCR buffer $(1.5 \mathrm{mM}$ $\mathrm{MgCl}_{2}$ and $125 \mu \mathrm{M}$ each dNTP), $250 \mathrm{nM}$ each forward and reverse primer, 0.5 unit of GoTaq polymerase (Promega Corp.), and 25 to $60 \mathrm{ng}$ of genomic DNA. The PCR reactions were performed with an initial denaturation at $95^{\circ} \mathrm{C}$ for $5 \mathrm{~min}$; followed by 38 cycles of $30 \mathrm{~s}$ at $94^{\circ} \mathrm{C}, 30 \mathrm{~s}$ at $52^{\circ} \mathrm{C}$, and $45 \mathrm{~s}(60 \mathrm{~s}$ for ef $1 /$ ef 2$)$ at $72^{\circ} \mathrm{C}$; and a final elongation step of $5 \mathrm{~min}$ at $72^{\circ} \mathrm{C}$ (Table 2). PCR products were purified with a Wizard SV Gel and PCR clean-up system (Promega Corp.) for DNA sequencing with BigDye terminator reagent (Applied Biosystems) following the manufacturer's instructions. All purified PCR products were sequenced at the University of Calgary. The DNA sequences obtained were manually adjusted and aligned using ClustalW embedded in the BioEdit v7.1.3 (17).

Based on the phylogenetic analysis described below, 1 F. redolens isolate from clade I, 3 isolates from clades II to V (Fig. 1), and 16 isolates from clade VI were characterized morphologically after 7 to 10 days of growth on 60-by-15-mm PDA and 14 to 21 days on carnation leaf-piece agar (CLA) with $12 \mathrm{~h}$ of lighting at room temperature (16). A volume of $20 \mu \mathrm{l}$ of $30 \%$ glycerine was pipetted onto the CLA surface, and spores were then harvested to make slides for examination under a Zeiss AxioImager M1 fluorescent microscope (Carl Zeiss). Digital images of conidia were taken under the $\times 40$ objective lens, and the length and width of 20 conidia of selected isolates of each species were estimated with the aid of image analysis software AxioVision v4.8.2.

The ITS and EF- $1 \alpha$ DNA sequences of each isolate from each phylogenetic clade were aligned by means of the BLASTn algorithm at the National Center for Biotechnology Information web-

Table 2. Primers used for polymerase chain reaction and DNA sequencing in this study

\begin{tabular}{llcc}
\hline Primer & \multicolumn{1}{c}{ Sequence $\left(\mathbf{5}^{\prime}-\mathbf{3}^{\prime}\right)$} & $\begin{array}{c}\text { Temp } \\
\left({ }^{\circ} \mathbf{C}\right)^{\mathbf{a}}\end{array}$ & $\begin{array}{c}\text { Time } \\
(\mathbf{s})^{\mathbf{b}}\end{array}$ \\
\hline ITS 5 & GGAAGTAAAAGTCGTAACAAGG & 52 & 45 \\
ITS 4 & TCCTCCGCTTATTGATATGC & $\ldots$ & $\ldots$ \\
EF-1 & ATGGGTAAGGA(A/G)GACAAGAC & 52 & 60 \\
EF-2 & GGA(G/A)GTACCAGT(G/C)ATCATGTT & $\ldots$ & $\ldots$ \\
J1AF & GCTAATTCTTAACTTACTAGGGGCC & 60 & 45 \\
J1AR & CTGTAATAGGTTATTTACATGGGCG & $\ldots$ & $\ldots$ \\
FaF & CAAGCATTGTCGCCACTCTC & 58 & 45 \\
FaR & GTTTGGCTCTACCGGGACTG & $\ldots$ & $\ldots$ \\
\hline
\end{tabular}

\footnotetext{
a Annealing temperature.
}

${ }^{\mathrm{b}}$ Extension time. site and the Fusarium-specific database (FUSARIUM-ID) to identify species using 97 to $100 \%$ sequence identity as the threshold to identify isolates to their corresponding species. If an isolate had 97 to $100 \%$ sequence identity to more than one known species, further species identification was performed by employing the PCR-based assays, phylogenetic analyses, and conidial characterization. All species identification was based on a combination of molecular phylogenetic results and morphological characterizations.

Phylogenetic analysis. All of the obtained sequences used for phylogenetic analyses were deposited in GenBank (accession number JX534245-500). The sequence characters were weighted equally in all phylogenetic analyses.

Bayesian inference (BI) was applied to estimate phylogenetic relationships among isolates using MrBayes v3.1.2 (20,35), with $F$. oxysporum as an outgroup. Prior to BI analysis, the best-fit nucleotide substitution model was selected using the program ModelTest 3.7 (34). BI was performed with four chains (one cold and three heated under default heating values) in each of two parallel runs, with each chain starting with a random tree, and subsequently run for 2,000,000 generations. Trees were sampled every 100 generations. Based on the 40,002 trees sampled, a consensus tree was calculated after omitting the first $25 \%$ of the trees as burn in.

Maximum parsimony (MP) analysis was performed with PAUP v $4.0 b 10$ (39). Gaps were treated as a "fifth base" because the sequence gaps generally provide significant phylogenetic signals. The heuristic searches were conducted using tree-bisection-reconnection branch-swapping with 200 random additional replicates, with unordered character option (100 random replications, starting seed 678756052 for ITS and 290116450 for EF-1 $\alpha$ sequences). Bootstrap support values (11) were calculated from the 200 replicate analyses, using a single random addition replication per bootstrap resampling. All phylogenetic trees were graphically edited with FigTree v1.3.1 (http://tree.bio.ed.ac.uk/software/figtree/) to produce figures.

Pathogenicity tests. The 128 isolates of Fusarium were tested for their pathogenicity on canola '45H29' (Pioneer Hi-Bred), a widely grown cultivar in Alberta and susceptible to Fusarium spp. For each single-conidium-derived isolate, two 8-mm-diameter agar plugs with live mycelium were cut and transferred to two separate PDA plates and incubated at room temperature under $12 \mathrm{~h}$ of ambient room lighting for 13 to 15 days. The two PDA plates fully covered with mycelium ( $30 \mathrm{ml}$ of propagulae, in total, for each isolate) were cut into pieces of approximately 1 to $2 \mathrm{~mm}^{2}$ and suspended in about $90 \mathrm{ml}$ of distilled water. A 20-ml aliquot of the suspension was evenly added to the surface of a 13-cm-diameter plastic cup filled with $500 \mathrm{ml}$ of sterilized Promix PGX soil (Evergro Canada Inc.). Ten seeds of $45 \mathrm{H} 29$ canola were sown on the top of each plastic cup, covered with $40 \mathrm{ml}$ of the same sterilized Promix PGX soil, and grown at about $25^{\circ} \mathrm{C}$ under a 12 -h photoperiod in a greenhouse. Two PDA plates without any fungal colonization were suspended in distilled water and inoculated onto the plants as previously described to serve as the negative control. For each isolate, six replications (cups) were inoculated. Cups were placed randomly following a randomized complete block design.

When sunken brown lesions were observed on the basal stem, canola plants were collected and washed under tap water 20 days after inoculation. The washed roots were assessed for presence and severity of root rot symptoms on a 0 -to-4 scale according to Hwang et al. (22), where $0=$ no symptoms, $1=$ light symptoms (discoloration but no visible lesions), $2=$ obvious lesions, $3=$ severe lesions on the stem and diminished plant vigor, and $4=$ stem rotten and plant dead. The pathogenicity test of all isolates on canola $45 \mathrm{H} 29$ was repeated once under the same greenhouse conditions. A nonparametric marginal effects analysis was performed to determine the root rot severity within each species using an SAS macro (available for download at http://www.ams.med.unigoettingen.de/makros/run_npar.html). The datasets consisted of the following variables: isolate, severity rating, and subject (a unique identifier that is needed for calculating confidence intervals; 38). Within each dataset, severity was ranked within each isolate, and 
analysis of variance of the ranks was conducted using the Proc Mixed option. The disease severity of each isolate on canola was represented by the estimated relative effects. Median and mean rank values for each isolate within the species were calculated and isolate with $i$ values outside the confidence interval for an isolate were deemed significantly different from that isolate.

\section{Results}

Phylogenetic analysis. In total, 128 Fusarium isolates were obtained from the 120 commercial fields in central Alberta in the summers of 2009, 2010, and 2011 (Table 1). The EF-1 $\alpha$ fragments from the 128 isolates ranged from 595 to $653 \mathrm{bp}$ and the number of

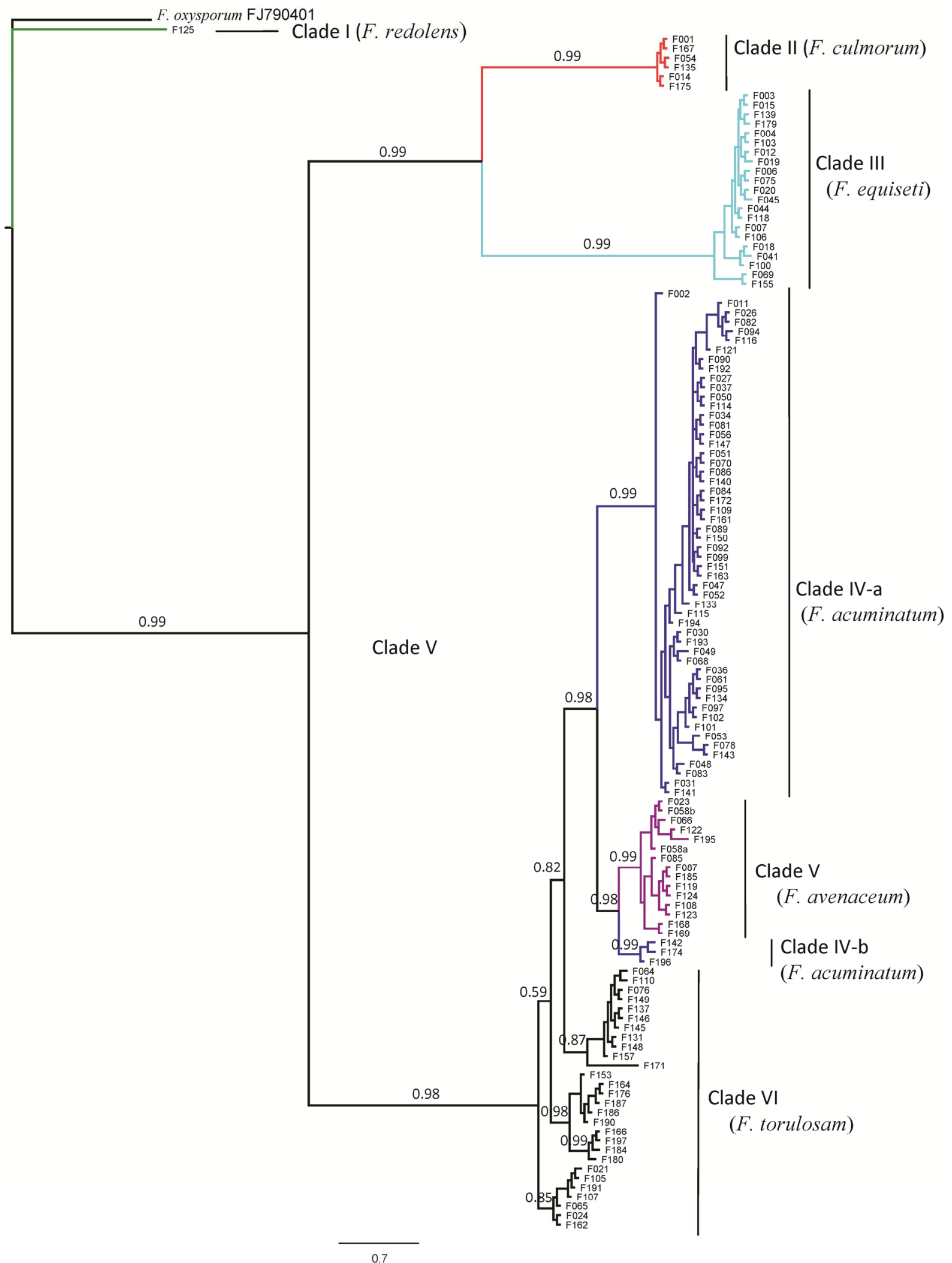

Fig. 1. Bayesian inference tree based on elongation factor $1-\alpha$ sequence data. Numbers above the branches indicate the posterior probabilities for each cluster. Phylogenetic clades are given based on the species identification. Clade I: Fusarium redolens, clade II: F. culmorum, clade III: F. equiseti, clade IVa and clade IVb: F. acuminatum, clade V: F. avenaceum, and clade VI: F. torulosum. 
sequence characters in the aligned sequence matrix was $680 . \mathrm{Nu}-$ cleotide frequencies were $\mathrm{A}=0.2354, \mathrm{C}=0.3034, \mathrm{G}=0.2003$, and $\mathrm{T}=0.2609$. After alignment with the BioEdit program, the data optimal nucleotide substitution model was applied to the data matrix. The best-fit model $(\mathrm{HKY}+\mathrm{G})$ was selected using the program ModelTest.
The ITS fragments from the 128 isolates ranged from 469 to 527 $\mathrm{bp}$ and the number of the sequence characters in the aligned sequence matrix was 531. The variation in length largely resulted from indels among the different species. Nucleotide frequencies were $\mathrm{A}=0.2697, \mathrm{C}=0.2645, \mathrm{G}=0.2305$, and $\mathrm{T}=0.2353$. After alignment with the BioEdit program, the data optimal nucleotide

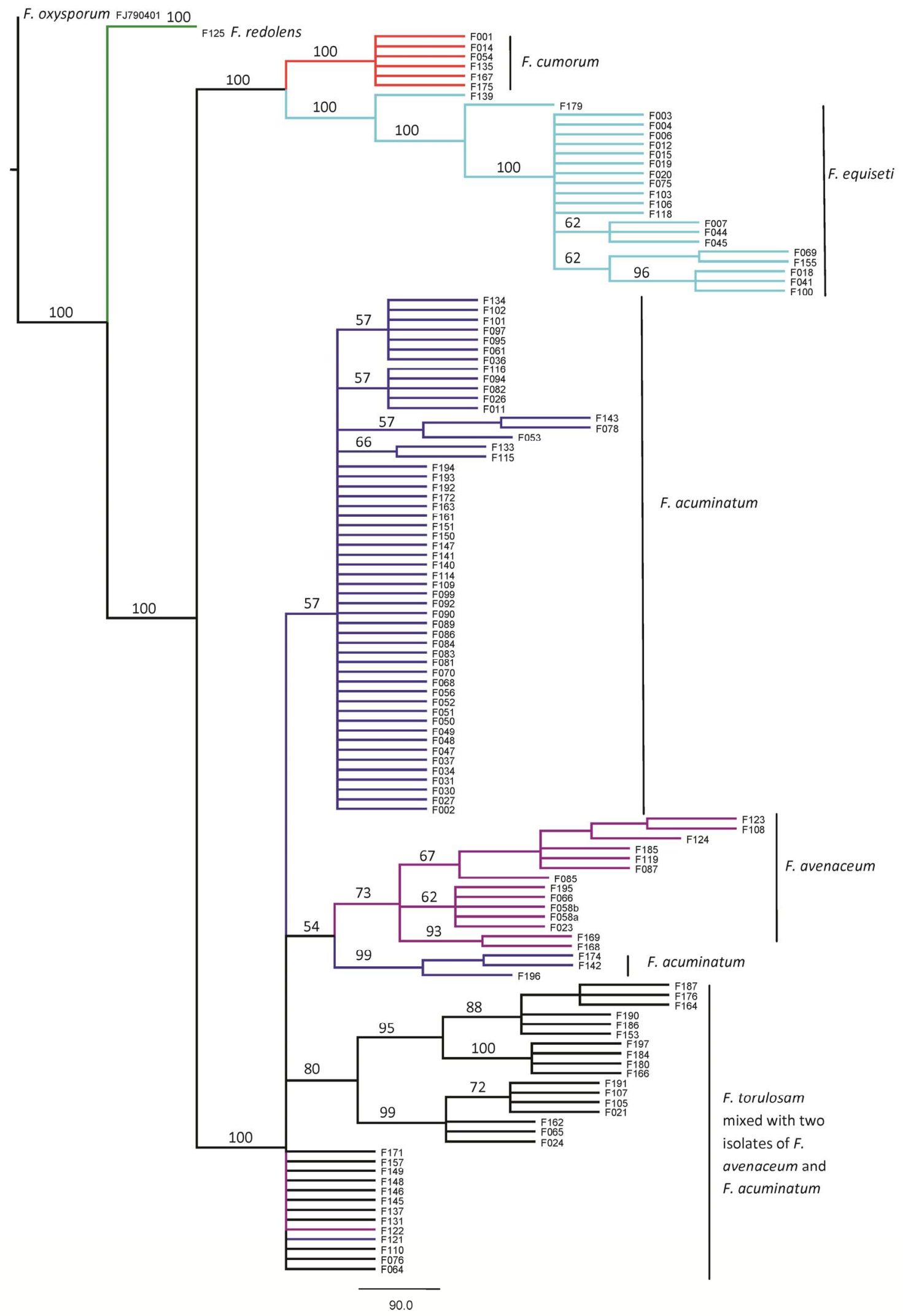

Fig. 2. Maximum parsimony consensus tree based on elongation factor $1-\alpha$ sequence data. Numbers above the branches indicate bootstrap support (percentage) for each cluster. 
substitution model was applied to the data matrix. The best-fit model $(\operatorname{TrNef}+\mathrm{G})$ was selected using the program ModelTest.

For MP analyses of the EF- $1 \alpha$ sequence data, 270 characters were parsimony-informative, 329 characters were constant, and 81 variable characters were parsimony-uninformative. The outgrouprooted major consensus tree is shown in Figure 2. For MP analyses of the ITS sequence data, 130 characters were parsimony-informative, 382 characters were constant, and 19 variable characters were parsimony-uninformative. The outgroup-rooted major consensus tree is shown in Figure 3.

Both the MP and BI analyses of the EF- $1 \alpha$ and ITS sequences yielded the same results for phylogenetic clades I, II, and III (Figs.

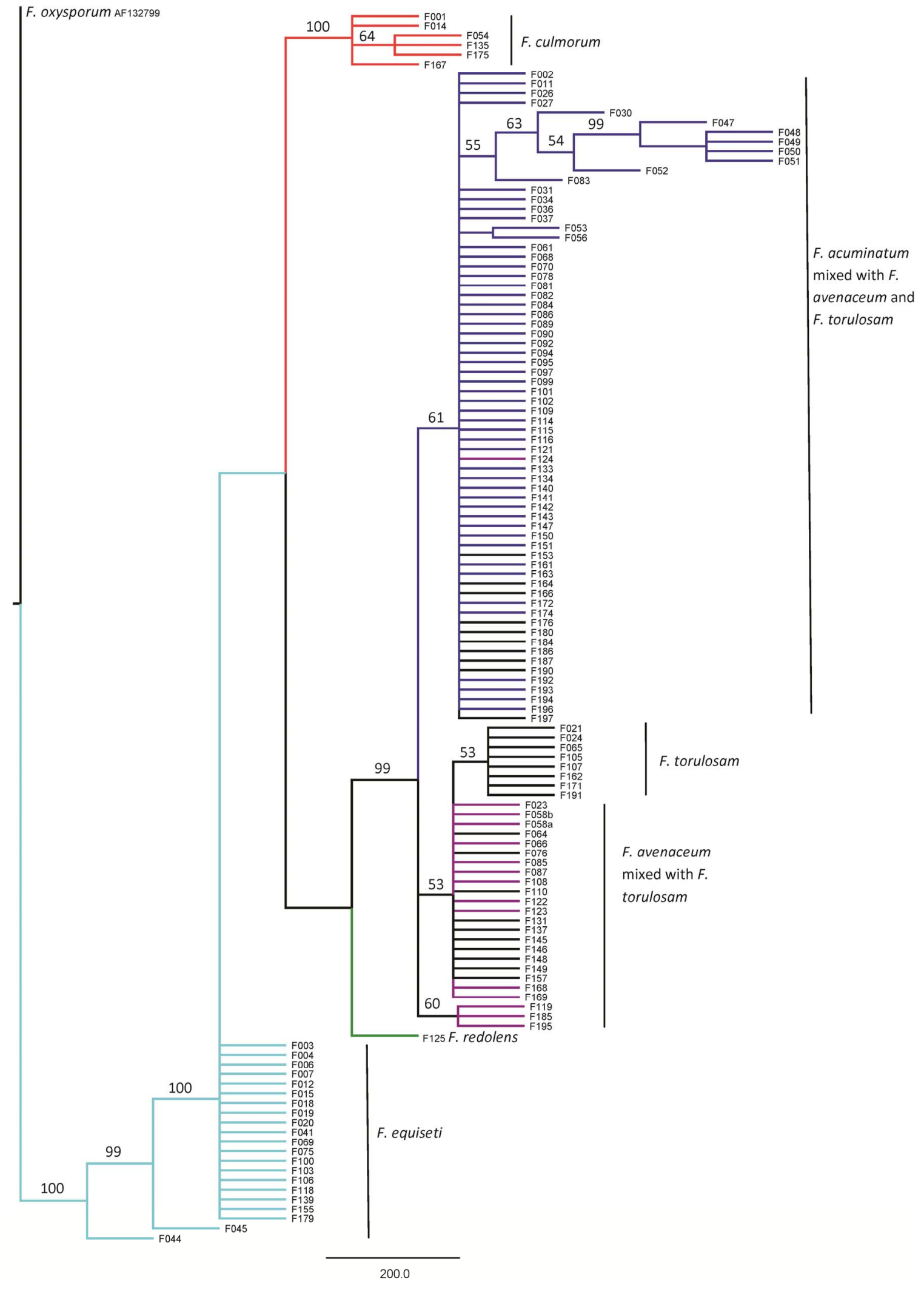

Fig. 3. Maximum parsimony consensus tree based on internal transcribed spacer sequence data. Numbers above the branches indicate bootstrap support (percentage) for each cluster. 
1-4). Isolate F125 was the only member of clade I (phylogenetic branch highlighted in green); isolates F001, F167, F054, F135, F014, and F175 were clustered together in clade II (highlighted red); and 21 isolates were clustered in clade III (highlighted in light blue) in all of the BI and MP trees. However, different tree topologies were observed among the BI and MP trees of the remaining 100 isolates of clades IV, V, and VI (Figs. 1-4).
Among the remaining 100 isolates, based on the EF-1 $\alpha$ sequence data, 54 isolates were clustered in clade IV-a of the BI tree, and 53 of these isolates were clustered together (branches highlighted as dark blue) in the MP tree (Figs. 1 and 2). Based on the ITS sequence data, 56 isolates were clustered together (55 dark blue branches and 1 pink branch) in the BI tree but 12 more isolates (11 black branches and 1 dark blue branch) were clustered

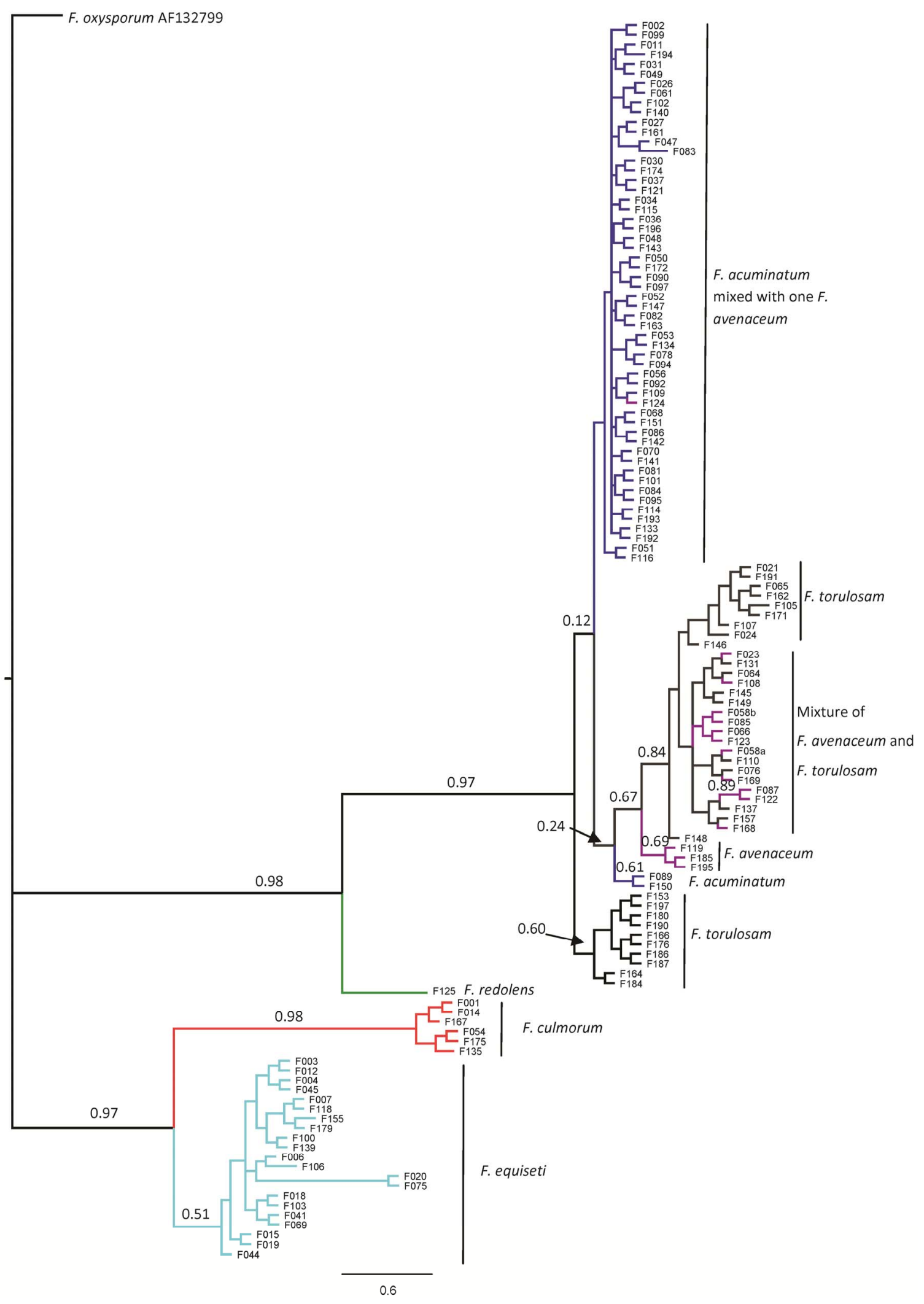

Fig. 4. Bayesian inference tree based on internal transcribed spacer sequence data. Numbers above the branches indicate posterior probabilities for each cluster. 
together in the MP tree (Figs. 3 and 4). In the BI tree generated with the EF-1 $\alpha$ data, isolates F089 and F150 were included in clade IV-a but isolates F124, F142, F174, and F196 were not.

For the clade V, based on the EF-1 $\alpha$ sequence, 15 isolates (highlighted in pink) were clustered together in the BI tree but isolate F122 was not clustered together with the other 14 isolates in the MP tree (Figs. 1 and 2).

The phylogenetic relationships of the remaining isolates were complex because their topological positions were different in the phylogenetic trees (Figs. 1-4). Based on the EF-1 $\alpha$ sequence data, the isolates formed four subclades on the BI tree (Fig. 1) but only two subclades on the MP tree (Fig. 2). Based on the ITS sequence data, two subclades were formed on both the BI and MP trees.

Species identification. Two sets of $F$. avenaceum-specific primers, FaF/FaR and J1AF/J1AR, were used for PCR-based identification of all 128 isolates. Amplicons of the target fragments were obtained from 15 isolates (11.7\% of the total number) with the primer pair $\mathrm{J} 1 \mathrm{AF} / \mathrm{J} 1 \mathrm{AR}$ and from 61 isolates $(47.7 \%$ of the total number) with primer pair $\mathrm{FaF} / \mathrm{FaR}$ (Table 2). Those 15 isolates, which produced the target fragments with the primers J1AF/J1AR, were clustered to a clade with 0.99 posterior probabilities in the BI tree based on the EF- $1 \alpha$ sequence data. Isolate F122 was excluded from this clade in the MP tree, because its EF-1 $\alpha$ sequence information was not readable in the MP tree construction. However, F122 clustered into the same clade with other $F$. avenaceum isolates in both the BI and MP trees based on the ITS data, with strong support of its phylogenetic position in the $F$. avenaceum clade (clade V; the posterior probability was 0.84 in the BI tree and the bootstrap value was $53 \%$ in the MP tree).

There were three more isolates (F142, F174, and F196) which had a close relationship to the $15 \mathrm{~F}$. avenaceum isolates, with a high posterior probability value, which could be clustered into one clade. However, no target bands were obtained from these three isolates with the primers $\mathrm{J} 1 \mathrm{AF} / \mathrm{J} 1 \mathrm{AR}$. They clustered together with other isolates on the BI tree based on the ITS data. And, because macroconidia of these three isolates were wider and much shorter than expected for $F$. avenaceum, F142, F174, and F196 did not match the description for this species. The macroconidia of the 15 isolates described above were very long and slender, with a thin wall and slightly curved appearance. The average size of the mac- roconidia was 65 by $3.5 \mu \mathrm{m}$. The apical cell was long and tapering to a point and the basal cell was notched (Fig. 5d). Three to five septa were observed. No microconidia were seen in these isolates (Fig. 5d). Based on the phylogenetic analyses and the conidial characteristics, those 15 isolates $(11.7 \%$ of the total number of isolates) that produced the target fragment with primer set $\mathrm{J} 1 \mathrm{AF} / \mathrm{J} 1 \mathrm{AR}$ were identified as $F$. avenaceum. Based on a comparison of the phylogenetic trees and megablast results of the EF- $1 \alpha$ and ITS sequence data with the nucleotide collection database of GenBank, only one isolate, F125, was identified as $F$. redolens (Fig. 5c), with $100 \%$ sequence identity to the published EF- $1 \alpha$ sequences of $F$. redolens (GenBank accession number HQ731063; $0.8 \%$ of the total number of isolates) (25); six isolates (F001, F167, F054, F135, F014, and F175) were identified as F. culmorum (Fig. 5a), with 99 to $100 \%$ sequence identity to the published EF-1 $\alpha$ sequences of $F$. culmorum (GenBank accession numbers JF278585-90 and GU370469-70; 4.7\%) (30); and 21 isolates (F003, F015, F139, F179, F004, F103, F012, F019, F006, F075, F020, F045, F044, F118, F007, F106, F018, F041, F100, F069, and F155) were identified as F. equiseti species complex (Fig. 5b), with 96 to $99 \%$ sequence identity (16.4\%; GenBank accession numbers HQ702572, FJ939679-80, and GQ505599). The species identification results based on phylogenetic relationship were confirmed for these three species by the shapes and sizes of their macroconidia, together with the characteristics of the microconidia on CLA plates (26; Fig. 5b).

Isolate $\mathrm{F} 125$ ( $F$. redolens) produced robust and thick-walled macroconidia (Fig. 5c), with average dimensions of 37 by $5.4 \mu \mathrm{m}$, and microconidia with dimensions of 9.2 by $4.2 \mu \mathrm{m}$. The widest part was at the upper third of the macroconidia and each had a hooked apical cell and slightly foot-shaped basal cell. The macroconidia of $F$. culmorum isolates were robust, relatively short, quite wide relative to their length and thick walled, with an average size of 37 by $6.8 \mu \mathrm{m}$ for macroconidia (Fig. 5a). The widest part was at the midpoint of the macroconidium, and it had a rounded and blunt apical cell. The basal cell was notched and without a distinct foot shape. No microconidia were observed for this species.

The isolates of $F$. equiseti had long and slender macroconidia with a similar shape and size, and usually had five septa. The average dimensions of the macroconidia were 55 by $4.4 \mu \mathrm{m}$. The apical
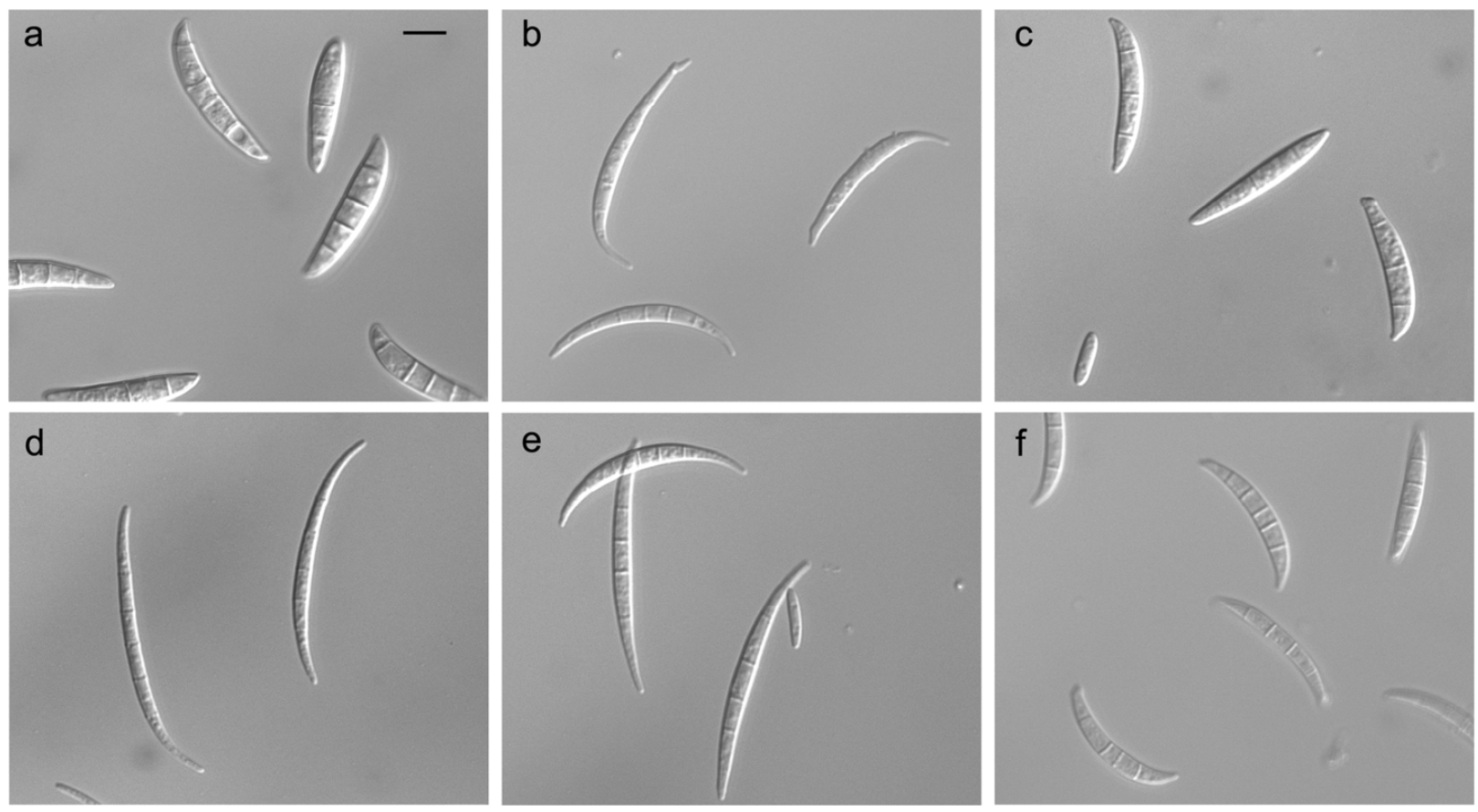

Fig. 5. Microscope images of conidia from representative isolates of identified species. The scale bar corresponds to $10 \mu \mathrm{m}$. a, Macroconidia of Fusarium culmorum (F001); b, macroconidia of $F$. equiseti (F106); c, macroconidia and microconidia of $F$. redolens (F125); d, macroconidia of $F$. avenaceum (F087); e, macroconidia and microconidia of F. acuminatum (F194); and f, macroconidia of F. torulosum (F021). 
cell was tapered and elongated and the basal cell had an obvious foot-shape (Fig. 5b).

The 54 isolates of clade IV-a (Fig. 1) were clustered together in all phylogenetic trees. Three more isolates of clade IV-b were clustered together with the above 54 isolates based on the ITS sequences (Figs. 3 and 4 ) and were not identified as $F$. avenaceum based on PCR assay results or conidial characteristics; therefore, these 57 isolates ( $44.5 \%$ of the total) were identified as F. acuminatum, a designation supported by the blast results obtained with the EF- $1 \alpha$ and ITS sequence data. Moreover, this designation was confirmed by the conidial characteristics of these isolates. The macroconidia were thick walled and the curvature of the conidia was moderately equal. The average size of the macroconidia was 52 by $3.9 \mu \mathrm{m}$. Their basal cells had a distinct foot shape. The apical cell tapered and was slightly elongated (Fig. 5e). Sparse microconidia were observed in cultures of a few of isolates.

For the remaining 28 isolates, species identification was more difficult and complex. Based on blast results of the EF- $1 \alpha$ sequence of isolate F076 in the Fusarium-ID and Fusarium MLST databases, the most closely matched species were $F$. negundis and F. tricinctum, with 96.1 and $96.8 \%$ identity, respectively. Based on the ITS sequence of F076, the most closely matched species were $F$. flocciferum and $F$. tricinctum, with $99.8 \%$ identity in the Fusarium-ID database, and F. tricinctum, with $100 \%$ identity in the Fusarium MLST database. Based on the blast results of the EF-1 $\alpha$ and ITS sequence of isolate F076 against the nucleotide collection database of GenBank (blastn suite), the most closely matched species were F. flocciferum (KC999486 and AJ543574), F. torulosum (KC999484-5), F. tricinctum (HQ702589, KF381076, and GQ922561), and $F$. avenaceum (EU255800-04), all with 96 to $100 \%$ identity. For isolate F171, the most closely matched species were $F$. flocciferum (JX397824-25) and $F$ reticulatum (DQ854864), with 99 and 97\% identity, respectively, based on the EF-1 $\alpha$ sequence; and $F$. flocciferum (GQ505465) and $F$. tricinctum (JF273496,) with $100 \%$ identity based on the ITS sequence blast result against the GenBank database. These 28 isolates was assigned to four species- $F$. reticulatum, $F$. flocciferum, $F$. tricinctum, or F. torulosum-based on the blast results for each isolate (above $98 \%$ identity to the reference sequence; data not shown). Morphological examination revealed that the characteristics of the macroconidia were similar for all of the 28 isolates. Macroconidia with three to five septa were common for most of the isolates. The average size of the macroconidia was 36 by $4.6 \mu \mathrm{m}$. The basal cells had a slight foot shape and microconidia were absent or very rare (Fig. 5f). Therefore, they could not be $F$. tricinctum because $F$. tricinctum produces abundant microconidia on its aerial mycelia (26). F. reticulatum is a common synonym of $F$. heterosporum Nees \& T. Nees but the shape of the macroconidia of $F$. heterosporum is slender and straight or gently curved, which was different from that of the 28 isolates. These 28 isolates were identified as belonging to the $F$. torulosum species complex, because the conidial characteristics closely matched the species description. The macroconidia of $F$. torulosum are comparatively short and falcate with pointed apical cell and foot-shaped basal cell and three to five septa, and microconidia are absent or very rare (26).

Pathogenicity tests. Sunken brown lesions were observed on the stems of diseased canola plants 20 days after inoculation. Based on the results from the nonparametric marginal effects analysis of the severity values in the pathogenicity tests, aggressiveness of Fusarium isolates varied in all species (Table 1). Median disease rating of isolates were 0.4 to 3.7 in $F$. avenaceum, 0.4 to 3.1 in $F$. acuminatum, 0.2 to 1.5 in $F$. culmorum, 0.0 to 1.9 in $F$. equiseti, 0.3 to 1.7 in $F$. torulosum, and 0.7 in $F$. redolens. In $F$. avenaceum, three pathogenicity groups could be distinguished, based on aggressiveness on canola. F058a, F085, F087, F168, F169, and F185 were highly aggressive on canola (median disease rating of 3.3 to 3.7, estimated relative effect of 66.6 to 75.8), while F023, F058b, F108, F122, and F123 were less aggressive on canola (median disease rating of 0.4 to 0.9 , estimated relative effect of 11.4 to 26.2). The other four isolates showed moderate aggressiveness on canola. In F. culmorum, three isolates (F001, F167, and F175) showed higher aggressiveness, while two isolates (F014 and F054) were less aggressive on canola. However, for the other species, the aggressiveness on canola varied among the isolates. In F. acuminatum, one isolate (F174) showed significantly higher aggressiveness on canola. Within F. torulosum, F186 showed significantly higher aggressiveness on canola. In F. equiseti, F004 was the most highly aggressive on canola compared with other isolates in this species. There was no correlation between disease severity and locations in any species.

\section{Discussion}

Fusarium seedling blight, caused by Fusarium spp., is one of several seedling diseases in canola (3). The pathogens can cause damping off and root rot (21). Fusarium wilt, caused by F. oxysporum and $F$. avenaceum, has emerged as a disease of canola in recent years (25). The symptoms of Fusarium wilt include yellowing, wilting, and dark-brown or black discoloration of the vascular tissue on one side of the stem $(4,25)$. These symptoms are distinct from those associated with Fusarium seedling blight and root rot of canola. In the current study, 15 isolates of $F$. avenaceum were identified from root tissues showing typical symptoms of root rot but no isolates of $F$. oxysporum were collected. In all, 57 (44.5\%) of 128 Fusarium isolates were classified as $F$. acuminatum, which was the predominant Fusarium sp. isolated from the sampled canola fields. These results suggest that Fusarium seedling blight and root rot may now be more important diseases of canola in Alberta than Fusarium wilt, which could reflect the widespread cropping of canola cultivars with effective resistance against the latter.

The composition of Fusarium spp. collected from canola in the current study differs from that found in other crops in recent reports; F. avenaceum was identified as the primary causal pathogen of root rot on pea (Pisum sativum) and lupin (Lupinus angustifolius) in Alberta $(12,19)$. High levels of genotypic diversity were detected among the $F$. avenaceum isolates from lupin fields in central Alberta (19). For the 15 isolates of $F$. avenaceum in the current study, genetic diversity was relatively low and this species was not the predominant Fusarium pathogen of canola in central Alberta, although eight of the $F$. avenaceum isolates were among the most highly aggressiveness on canola. Target bands were obtained only from these 15 isolates with the primer set J1AF/J1AR. However, obvious target bands were also obtained from 12 isolates of $F$. avenaceum and 26 isolates of $F$. acuminatum with the primer set $\mathrm{FaF} / \mathrm{FaR}$. The results of PCR-based assays indicated that the species concept of $F$. avenaceum for primer set $\mathrm{J} 1 \mathrm{AF} / \mathrm{J} 1 \mathrm{AR}$ was much stricter and narrower than that of primer set FaF/FaR.

For species identification, a clear phylogenetic relationship was shown to exist for $F$. redolens, $F$. culmorum, and $F$. equiseti, and similar but distinct topologic structures were constructed for $F$. avenaceum, $F$. acuminatum, and $F$. torulosum in the phylogenetic trees based on the EF- $1 \alpha$ and ITS sequences. Phylogenetic analysis of multilocus sequence data using BI and MP analysis showed that F. culmorum from wheat is a single phylogenetic species, with no significant linkage disequilibrium and little or no lineage development related to geographic origin (30). The EF-1 $\alpha$ sequence of $F$. redolens isolate $\mathrm{F} 125$ had a $100 \%$ sequence identity to the $F$. redolens isolate 34.92 (HQ731063), which was isolated from chickpea (Cicer arietinum) in Spain (25) and an isolate of F. redolens from Italy (accession number EU281660), indicating that genetic diversity might be low for this species. The isolates of $F$. equiseti were clustered to a distinct clade in all of the phylogenetic trees, which coincides with results of research on human Fusarium pathogens (33). The phylogenetic relationships for species of $F$. avenaceum, $F$. acuminatum, and $F$. torulosum were very close, especially in the phylogenetic trees based on the ITS sequences, but they could be differentiated from each other by the phylogenetic trees based on the EF- $1 \alpha$ sequences as well as by their conidial characteristics. However, the reverse situation existed between $F$. redolens and $F$. oxysporum f. sp. ciceris. $F$. redolens is not easily differentiated from F. oxysporum f. sp. ciceris using morphology-based diagnosis 
but molecular protocols helped to avoid misdiagnoses in chickpea (25). Both molecular phylogenetic analyses and morphological characterization were used for all of the isolate identifications in this study to avoid any misdiagnoses.

The ITS region is a primary fungal barcode marker (37) and EF$1 \alpha$ is an excellent phylogenetic marker for resolving phylogenetic relationships within the Fusarium genus (15). Both DNA regions are good DNA barcode markers for the genus Fusarium, and their universality is suggested by the observation that DNA fragments from both regions could be successfully amplified and sequenced from all of the Fusarium isolates in this study. Within the most recently updated database FUSARIUM-ID, portions of the EF- $1 \alpha$, RPB2, ITS + LSU rDNA, and RPB1 genes were used for species identification (31). However, it is not necessary for all of these genes to be used for species identification or the analysis of phylogenetic relationships. The core barcode system has been separately standardized for animals, land plants, and fungi, and generally consists of less than three DNA regions $(7,18,37)$. In MP analyses of this study, 270 parsimony-informative characters were found for the EF- $1 \alpha$ sequence, which were higher than the 130 parsimony-informative characters for the ITS sequence. Additionally, $F$. avenaceum, $F$. acuminatum, and $F$. torulosum could be differentiated from each other based on phylogenetic trees of EF- $1 \alpha$ sequences but not based on the ITS sequences (Figs. 1-4). This shows that the EF- $1 \alpha$ sequence could provide more phylogenetic information than the ITS region within the Fusarium genus, which agreed with the results of Watanabe et al. (42).

For $F$. avenaceum identification, two specific primer sets, $\mathrm{FaF} / \mathrm{FaR}$ and $\mathrm{J} 1 \mathrm{AF} / \mathrm{J} 1 \mathrm{AR}$, were used and combined with the phylogenetic approach from ITS and EF-1 $\alpha$ sequences and morphological characteristics. The results of PCR assays using two primer sets were distinct from each other. Only 15 isolates produced target bands with $\mathrm{J} 1 \mathrm{AF} / \mathrm{J} 1 \mathrm{AR}$ but 61 isolates had positive amplification with $\mathrm{FaF} / \mathrm{FaR}$. The primer set $\mathrm{J} 1 \mathrm{AF} / \mathrm{J} 1 \mathrm{AR}$ was developed to detect $F$. avenaceum, with $F$. tricinctum, $F$. culmorum, $F$. graminearum, and $F$. poae as some of the reference species (41). F. avenaceum and $F$. tricinctum have similar colony morphologies on PDA but can be distinguished by the shape of their macroconidia, which are falcate in the former and almost lunate in the latter (26). ITS restriction fragment length polymorphism marker data also revealed a close relationship between $F$. avenaceum and $F$. tricinctum (41). The primer set $\mathrm{FaF} / \mathrm{FaR}$ was developed to detect $F$. avenaceum using F. culmorum, F. poae, F. graminearum, and some other species as reference; however, no closely related species such as $F$. tricinctum or F. acuminatum were used (9). Based on the results of this study, the primer set $\mathrm{FaF} / \mathrm{FaR}$ could not distinguish $F$. avenaceum from $F$. acuminatum; therefore, it was not reliable for identification of $F$. avenaceum in the present study. Additionally, with the same primer set, PCR conditions such as the composition of the PCR reaction mixture and the amplification parameters also affected the results. Using the DNA sequence of a specific gene region could avoid this problem. This is the reason for DNA barcoding, an approach to identify species based on sequences from a short, standardized DNA region, which was developed for the identification of organisms $(5,7,18,37)$. In this study, 128 isolates belonging to six species of Fusarium were tested for aggressiveness on canola. Among them, only one isolate belonged to $F$. redolens. Light disease symptoms were shown and could be rated as 0.68 (average data from different replicates). In total, 57 isolates were identified as $F$. acuminatum, which was the predominant species in the sampled canola fields in central Alberta. However, their aggressiveness on canola varied. The second most predominant species was $F$. torulosum, with 28 isolates. One isolate was more highly aggressive on canola compared with the other isolates. F. avenaceum was one of the pathogens causing seedling blight and root rot $(4,21)$. However, 15 isolates were identified in the present study. Six isolates ( $40 \%$ of the species) showed an extremely high aggressiveness on canola, with disease ratings of 3.3 to 3.7. However, five of the isolates (F023, F058b, F108, F122, and F123) were much less aggressive on canola (disease ratings of 0.4 to 0.9 ).
This indicated that there were variations of aggressiveness within the species.

Most of the previous evaluations of genetic diversity and aggressiveness of Fusarium spp. were focused on only a single species $(1,12,19,24,28)$. The current study attempted an examination of composition of the Fusarium pathogen complex on canola in central Alberta, and revealed the presence of at least six Fusarium spp. associated with seedling blight or root rot of canola. Although different species showed different levels of aggressiveness on canola, some isolates belonging to $F$. avenaceum were highly aggressive. However, among these species, the number of $F$. acuminatum isolates indicated that it was the predominant.

\section{Acknowledgments}

We thank the Alberta Crop Industry Development Fund Ltd., Canola Agronomic Research Program (Alberta Canola Producers Commission, Manitoba Canola Growers Association, SaskCanola, and the Canola Council of Canada), and the Alberta Innovates-Bio Solutions for their financial support of this study; and Y. L. Yang and H. T. Fu of Crop Diversification Center North for their technical assistance on this study.

\section{Literature Cited}

1. Alves-Santos, F. M., Benito, E. P., Eslava, A. P., and Diaz-Minguez, J. M. 1999. Genetic diversity of Fusarium oxysporum strains from common bean fields in Spain. Appl. Environ. Microbiol. 65:3335-3340.

2. Azor, M., Cano, J., Gene, J., and Guarro, J. 2009. High genetic diversity and poor in vitro response to antifungals of clinical strains of Fusarium oxysporum. J. Antimicrob. Chemother. 63:1152-1155.

3. Bailey, K. L., Gossen, B. D., Gugel, R. K., and Morrall, R. A. A. 2003. Diseases of Field Crops in Canada, 3rd ed. The Canadian Phytopathological Society, Saskatoon, SK, Canada.

4. Benard, D., Lange, R. M., and Harrison, L. M. 2001. Survey of Fusarium wilt and other canola diseases in Alberta, 2000. Can. Plant Dis. Surv. 81:102-104.

5. CBOL Plant Working Group. 2009. A DNA barcode for land plants. Proc Natl. Acad. Sci. USA 106:12794-12797.

6. Chen, Y. Y., Conner, R. L., Gillard, C. L., Boland, G. J., Babcock, C., Chang, K. F., Hwang, S. F., and Balasubramanian, P. M. 2007. A specific and sensitive method for the detection of Colletotrichum lindemuthianum in dry bean tissue. Plant Dis. 91:1271-1276.

7. China Plant BOL Group. 2011. Comparative analysis of a large dataset indicates that internal transcribed spacer (ITS) should be incorporated into the core barcode for seed plants. Proc. Natl. Acad. Sci. USA 108:1964119646.

8. Demeke, T., Clear, R. M., Patrick, S. K., and Gaba, D. 2005. Species-specific PCR-based assays for the detection of Fusarium species and a comparison with the whole seed agar plate method and trichothecene analysis. Int. J. Food Microbiol. 103:271-284.

9. Doohan, F. M., Parry, D. W., Jenkison, P., and Nicholson, P. 1998. The use of species-specific PCR based assays to analyse Fusarium ear blight of wheat. Plant Pathol. 47:197-205.

10. Edel, V., Steinberg, C., Gautheron, N., Recorbet, G., and Alabouvette, C. 2001. Genetic diversity of Fusarium oxysporum populations isolated from different soils in France. FEMS Microbiol. Ecol. 36:61-71.

11. Felsenstein, J. 1985. Confidence limits on phylogenetics: an approach using the bootstrap. Evolution 39:783-791.

12. Feng, J., Hwang, R., Chang, K. F., Hwang, S. F., Strelkov, S. E., Gossen, B. D., Conner, R. L., and Turnbull, G. D. 2010. Genetic variation in Fusarium avenaceum causing root rot on field pea. Plant Pathol. 59:845-852.

13. Feng, J., Hwang, R., Chang, K. F., Hwang, S. F., Strelkov, S. E., Gossen, B. D., and Zhou, Q. 2010. An inexpensive method for extraction of genomic DNA from fungal mycelia. Can. J. Plant Pathol. 32:396-401.

14. Fisher, N. L., Burgess, L. W., Toussoun, T. A., and Nelson, P. E. 1982. Carnation leaves as a substrate and for preserving cultures of Fusarium species. Phytopathology 72:151-153.

15. Geiser, D. M., Jiménez-Gasco, M. D., Kang, S., Makalowska, I., Veeraraghavan, N., Ward, T. J., Zhang, N., Kuldau, G. A., and O'Donnell, K. 2004. FUSARIUM-ID version 1.0: a DNA sequence database for identifying Fusarium. Eur. J. Plant Pathol. 110:473-479.

16. Grönberg, H., Paulin, L., and Sen, R. 2003. ITS probe development for specific detection of Rhizoctonia spp. and Suillus bovinus based on Southern blot and liquid hybridization-fragment length polymorphism. Mycol. Res. 107:428-438.

17. Hall, T. A. 1999. BioEdit: a user-friendly biological sequence alignment editor and analysis program for Windows 95/98/NT. Nucleic Acids Symp. Ser. 41:95-98.

18. Hebert, P. D. N., Cywinska, A., Ball, S. L., and de Waard, J. R. 2003. Biological identifications through DNA barcodes. Proc. R. Soc. Lond. B 270:313-321.

19. Holtz, M. D., Chang, K. F., Hwang, S. F., Gossen, B. D., and Strelkov, S. E. 2011. Characterization of Fusarium avenaceum from lupin in central Al- 
berta: genetic diversity, mating type and aggressiveness. Can. J. Plant Pathol. 33:61-76.

20. Huelsenbeck, J. P., and Ronquist, F. R. 2001. MrBAYES: Bayesian inference of phylogenetic trees. Bioinformatics 17:754-755.

21. Hwang, S. F., Ahmed, H. U., Gossen, B. D., Kutcher, H. R., Brandt, S. A., Strelkov, S. E., Chang, K. F., and Turnbull, G. D. 2009. Effect of crop rotation on the soil pathogen population dynamics and canola seedling establishment. Plant Pathol. J. 8:106-112.

22. Hwang, S. F., Howard. R. J., Chang, K. F., Park, B., and Burnett, P. A. 1994. Etiology and severity of Fusarium root rot of lentil in Alberta. Can. J. Plant Pathol. 16:295-303.

23. Jiménez-Fernández, D., Navas-Cortés, J. A., Montes-Borrego, M., JiménezDíaz, R. M., and Landa, B. B. 2011. Molecular and pathogenic characterization of Fusarium redolens, a new causal agent of Fusarium yellows in chickpea. Plant Dis. 95:860-870.

24. Kistler, H. C. 1997. Genetic diversity in the plant-pathogenic fungus Fusarium oxysporum. Phytopathology 87:474-479.

25. Lange, R. M., Gossmann, M., and Büttner, C. 2007. Yield loss in susceptible cultivars of spring rapeseed due to Fusarium wilt caused by Fusarium oxysporum. Commun. Agric. Appl. Biol. Sci. 72:723-734.

26. Leslie, J. F., and Summerell, B. A. 2006. The Fusarium Laboratory Manual. Blackwell Publishing Ltd., Oxford.

27. Li, D. Z., Liu, J. Q., Chen, Z. D., Wang, H., Ge, X. J., Zhou, S. L., Gao, L. M., Fu, C. X., and Chen, S. L. 2011. Plant DNA barcoding in China. J. Syst. Evol. 49:165-168.

28. Lori, G., Edel-Hermann, V., Gautheron, N., and Alabouvette, C. 2004. Genetic diversity of pathogenic and nonpathogenic populations of Fusarium oxysporum isolated from carnation fields in Argentina. Phytopathology 94:661-668.

29. Nash, S. M., and Snyder, W. C. 1962. Quantitative estimations by plat counts of propagules of the bean root rot Fusarium in field soils. Phytopathology 52:567-572.

30. Obanor, F., Erginbas-Orakci, G., Tunali, B., Nicol, J. M., and Chakraborty, S. 2010. Fusarium culmorum is a single phylogenetic species based on multilocus sequence analysis. Fungal Biol. 114:753-765.

31. O’Donnell, K., Humber, R. A., Geiser, D. M., Kang, S., Park, B., Robert, V. A. R. G., Crous, P. W., Johnston, P. R., Aoki, T., Rooney, A. P., and Rehner, S. A. 2012. Phylogenetic diversity of insecticolous fusaria inferred from multilocus DNA sequence data and their molecular identification via FUSARIUM-ID and Fusarium MLST. Mycologia 104:427-445.

32. O'Donnell, K., Kistler, H. C., Cigelnik, E., and Ploetz, R. C. 1998. Multiple evolutionary origins of the fungus causing Panama disease of banana: concordant evidence from nuclear and mitochondrial gene genealogies. Proc. Natl. Acad. Sci. USA 95:2044-2049.

33. O'Donnell, K., Sutton, D. A., Rinaldi, M. G., Gueidan, C., Crous, P. W., and Geiser, D. M. 2009. Novel multilocus sequence typing scheme reveals high genetic diversity of human pathogenic members of the Fusarium incar natum- $F$. equiseti and $F$. chlamydosporum species complexes within the United States. J. Clin. Microbiol. 47:3851-3861.

34. Posada, D., and Buckley, T. R. 2004. Model selection and model averaging in phylogenetics: advantages of the AIC and Bayesian approaches over likelihood ratio tests. Syst. Biol. 53:793-808.

35. Ronquist, F. R., and Huelsenbeck, J. P. 2003. MrBAYES 3: Bayesian phylogenetic inference under mixed models. Bioinformatics 19:1572-1574.

36. Schneider, R. 1958. Untersuchungen über Variabilität und Taxonomie von Fusarium avenaceum (Fr.) Sacc. Phytopathol. Z. 32:97-128.

37. Schoch, C. L., Seifert, K. A., Huhndorf, S., Robert, V., Spouge, J. L., Levesque, C. A., and Chen, W. 2012. Nuclear ribosomal internal transcribed spacer (ITS) region as a universal DNA barcode marker for fungi. Proc. Natl. Acad. Sci. USA 109:6241-6246.

38. Shah, D. A., and Madden, L. V. 2004. Nonparametric analysis of ordinal data in designed factorial experiments. Phytopathology 94:33-43.

39. Swofford, D. L. 2003. PAUP*. Phylogenetic Analysis Using Parsimony (*and Other Methods). Version 4. Sinauer Associates, Sunderland, MA.

40. Tan, M. K., and Niessen, L. M. 2003. Analysis of rDNA ITS sequences to determine genetic relationships among, and provide a basis for simplified diagnosis of, Fusarium species causing crown rot and head blight of cereals. Mycol. Res. 107:811-821.

41. Turner, A. S., Lees, A. K., Rezanoor, H. N., and Nicholson, P. 1998. Refinement of PCR-detection of Fusarium avenaceum and evidence from DNA marker studies for phenetic relatedness to Fusarium tricinctum. Plant Pathol. 47:278-288.

42. Watanabe, M., Yonezawa, T., Lee, K., Kumagai, S., Sugita-Konishi, Y Goto, K., and Hara-Kudo, Y. 2011.Molecular phylogeny of the higher and lower taxonomy of the Fusarium genus and differences in the evolutionary histories of multiple genes. BMC Evol. Biol. 11:322

43. White, T. J., Bruns, Y., Lee, S., and Taylor, J. 1990. Amplification and direct sequencing of fungal RNA genes for phylogenetics. In: PCR Protocols: A Guide to Methods and Applications. M. Innis, D. Gelfand, J. Sninsky, and T. White, eds. Academic Press, San Diego, CA.

44. Wollenweber, H. W, and Reinking, O. A. 1935. Die Fusarien, ihre Beschreibung, Schadwirkung und Bekampfung. Verlag Paul Parey, Berlin. 